\title{
Reflections
}

\section{No trenches: toward inclusive and hybrid methodologies - commentary to Tulumello}

\author{
GUNTRAM H. HERB
}

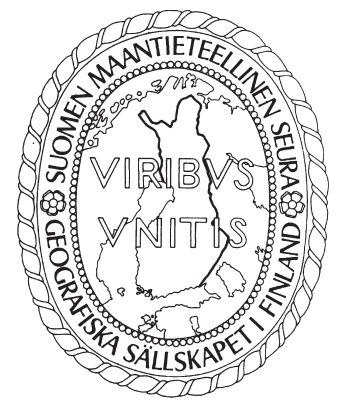

Herb, G. H. (2019) No trenches: toward inclusive and hybrid methodologies - commentary to Tulumello. Fennia 197(1) 155-157. https://doi.org/10.11143/fennia.79837

My critical reflection on Simone Tulumello's intervention focuses first on the need to make a clear distinction between methodologies and epistemologies, asking the author to explain his own perspective. A second area of concern is the analogy he draws between structures engineered with concrete and human societies and how this appears to simplify the debate he initiates. In the third part I suggest that the goal should be to transcend the tensions between paradigms through inclusive and hybrid methodologies.

Keywords: epistemologies, positivism, quantitative methodologies, qualitative methodologies

Guntram H. Herb, Department of Geography, Middlebury College, Middlebury, Vermont 05753 USA. E-mail: herb@middlebury.edu

Simone Tulumello, you are not simply throwing down the gauntlet, but you come out swinging and artfully dissect a positivist exemplar. I greatly appreciate the critical salvo that you fire with a 'common sense of the engineer' and your virtuous passion to level the epistemological playing field (Tulumello 2019). Your intervention reminds me of the battles over epistemologies in the 1970s-1990s that were carried out in conference panels, academic journals, and among faculty colleagues. It makes me think about the difference between epistemologies and methods, the analogy of engineering and human geography, and the need for inclusivity and hybridity in research. There is much to learn, but also some of concern in these three regards. In short, I have three critical remarks that are centered on: conceptualization, argumentation/analogy, and the goals of epistemological debates. My critique comes with a real sense of gratitude for this intervention. It is a stimulating piece - it made me think and I have a feeling it will keep me thinking for a while.

Conceptually, I am concerned with 1) the conflation of positivism and quantitative methods and 2) the binary of quantitative/positivist methods versus qualitative methods. You argue that there are links between quantification (large data sets and sample sizes), generalizations, and theory building - and that practitioners using quantitative methods deny qualitative methods the ability to generalize due to small data sets. But quantitative methods are not simply positivist, they are also used in other epistemologies, such as structuralism. Even if your concern is only with positivist quantitative methods, there is an imbalance here because you associate one method with an epistemology, but not the other. Given the wide range of epistemologies that use qualitative methods, which one are you championing in your piece? You advocate for qualitative methods, but do not foreground the assumptions or shortcomings of your own approach - even though you demand positivists do that. To help us better understand your argument, you need to explain how the context of the type of 
research you practice and your positionality influence the text you write. I looked up your work something that cannot be done in a double-blind review, and it provides a hint of your positionality. As Livingstone (1992) explained for the history of geography, it helped me consider how your text and context might be reciprocally constituted. Your argument makes sense in the context of your work in urban geography and planning. The preference for models, big data, and quantitative methods in these fields-and public statements about the superiority of epistemologies employing the "scientific method" (e.g. Shearmur 2008) - would certainly make it wearisome to publish even superbly designed qualitative case studies there, indeed. However, methods are not synonymous with epistemologies; you need to distinguish more clearly the two opposing camps you set up in your intervention.

The argumentation of your intervention is clever in that it seeks to destabilize quantitative/positivist methods from within by applying the 'common sense of the engineer'. You make a convincing argument that significant error lurks in positivist generalizations, but can you really compare the epistemology behind the construction of buildings to the complexity of human societies and human-environment interaction? Granted, you point out that human societies are "much more complex" than your example of concrete and that therefore even more error is to be accounted for in human societies, but you use this disclaimer only to justify increased vigilance about positivist work. I have two issues here. First, concrete is fundamentally different from society because there is no agency inherent in concrete. Yes, actor-network theory has shown that objects can have agency, but not in their own destruction. The analogy is therefore not fully applicable. Second, your 'concrete' analogy is essentially about true and false: whether the concrete structure collapses or whether it endures the weight placed on it. Quantitative social scientific research does not deal with such clear and definite outcomes and there are no such truth claims in the article by Ellen, Lens and O'Regan (2012) about housing vouchers that you dissect for potential errors in its findings. The authors of the article make a claim that contradicts existing explanations (backed up with evidence), but they do not posit that this is the only explanation. You argue that their evidence should be subjected to a larger margin of error and that the authors (and other positivist works for which you consider it to be an exemplar) should acknowledge that. But how did you arrive at the potential error of ${ }^{\prime} 0.2^{\prime}$ ? Positivists might claim the right to make generalizations, but their epistemology also embraces the incremental and contradictory progress of knowledge, with falsification of claims being key to the process.

Your intervention asks each epistemology to recognize and explicitly state its assumptions and its shortcomings and to respect and accept the "findings produced through different methodological and epistemological lenses" (Tulumello 2019,126). Such a call for self-critical reflexivity is laudable, even if it is not a new story. In the 1970 s and 1980s, feminist geographers had to convince their quantitative positivist modeling colleagues - the vast majority of whom were male - that the qualitative feminist approach to 'situated' knowledge was as insightful as a quantitative positivist one. Humanistic geographers such as Tuan had to defend the validity of their assertion that there were universal ways in which humans experience space, place and the environment. In the 1990s, postmodernists and post-structuralists rallied against metanarratives and prefaced their works with statements about positionality. But are we still mired in paradigmatic trench warfare? Emanating from your lines - at least in my reading - is a view that puts qualitative work in a position of victimhood. Ergo the need to tear down the supposed aura of superiority of quantitative/positivist geography. But why go only on the attack, why not also point out the unique and powerful insights of qualitative methods or, even better, showcase the shared merits of quantitative and qualitative methods?

In the end, the debate should not be about qualitative versus quantitative, but about respect, inclusivity, and hybridity. There are journals out there that are geared toward qualitative research and there are journals that are more wed to quantitative approaches, so there are ways to evade the epistemological assaults of 'Reviewer 2' on the integrity of your method. Other journals, such as Fennia and the Annals of the American Association of Geographers, cast a wide and welcoming net, epistemologically. More importantly, researchers increasingly triangulate methods to augment the robustness of their claims. Our world is not just marked by walls and Wallstreet profits, but also touched by flows and scapes that transcend b/orders. Given the ensuing relational spatiality linking global and local, humans and the more than human world, geographers can no longer study human societies effectively with a single method. The epistemological challenge is not to create a 
level playing field for warring approaches, but to celebrate methodological inclusivity and hybridity in our investigations.

\section{References}

Ellen, I. G., Lens, M. C. \& O'Regan, K. (2012) American murder mystery revisited: do housing voucher households cause crime? Housing Policy Debate 22(4) 551-572. https://doi.org/10.1080/10511482. 2012.697913

Livingstone, D. (1992) The Geographical Tradition: Episodes in the History of a Contested Enterprise. Blackwell, Oxford.

Shearmur, R. (2008) Chicago and L.A.: a clash of epistemologies. Urban Geography 29(2) 167-176. https://doi.org/10.2747/0272-3638.29.2.167

Tulumello, S. (2019) Generalization, epistemology and concrete: what can social sciences learn from the common sense of engineers. Fennia 197(1) 121-131. https://doi.org/10.11143/fennia.77626 